\title{
GPS meteorology project of Japan —Exploring frontiers of geodesy-
}

\author{
T. Tsuda ${ }^{1}$, K. Heki ${ }^{2}$, S. Miyazaki ${ }^{3}$, K. Aonashi ${ }^{4}$, K. Hirahara ${ }^{5}$ H. Nakamura ${ }^{4}$, M. Tobita ${ }^{3}$, F. Kimata ${ }^{5}$, T. Tabei ${ }^{6}$, \\ T. Matsushima ${ }^{7}$, F. Kimura ${ }^{8}$, M. Satomura ${ }^{9}$, T. Kato ${ }^{10}$, and I. Naito ${ }^{2}$ \\ ${ }^{1}$ Kyoto University, Uji, Kyoto 611-0011, Japan \\ ${ }^{2}$ National Astronomical Observatory, Mizusawa, Iwate 023-0861, Japan \\ ${ }^{3}$ Geographical Survey Institute, Tsukuba, Ibaraki 305-0811, Japan \\ ${ }^{4}$ Meteorological Research Institute, Tsukuba, Ibaraki 305-0052, Japan \\ ${ }^{5}$ Nagoya University, Nagoya 464-0814, Japan \\ ${ }^{6}$ Kochi University, Kochi 780-8520, Japan \\ ${ }^{7}$ Kyushu University, Fukuoka 812-0053, Japan \\ ${ }^{8}$ Tsukuba University, Tsukuba, Ibaraki 305-0006, Japan \\ ${ }^{9}$ Shizuoka University, Shizuoka 422-8017, Japan \\ ${ }^{10}$ University of Tokyo, Tokyo 113-0032, Japan
}

(Received August 24, 1998; Revised September 28, 1998; Accepted September 28, 1998)

\section{Water Vapor; from Geodetic Noise to Meteoro- logical Signal}

The Global Positioning System (GPS) is a satellite-based positioning system now widely used for navigation, relative positioning, and time transfer. Its high precision is applied for the continuous monitoring of positions of permanent stations for crustal deformation studies. A notable example is the nationwide GPS array run by the Geographical Survey Institute (GSI) of Japan, composed of nearly one thousand stations separated typically by $15-30 \mathrm{~km}$ from one another (see Tsuji et al., 1996, for details). It has proved its excellent performance in, for example, detecting slow earthquakes as shown in Fig. 1 (Heki et al., 1997).

The GPS array, however, often shows fluctuations of up to a few $\mathrm{cm}$ in estimated site coordinates, especially in the vertical, with time-scales of a week or so. This has been impeding earthquake prediction researches. Such fluctuations are larger in summer than in winter (see "North" component of Fig. 1). This suggests their origin in the refraction of microwave signals by ever-changing atmospheric water vapor, or they are partly caused by incomplete separation between atmospheric delay and site coordinates in the parameter estimation during GPS data processing. Japan is in a humid region surrounded by warm sea water of the western boundary current in the Northern Pacific. It is important to remove such errors to reveal true crustal deformations.

On the other hand, information on atmospheric water vapor is essential in predicting global climate changes and rainfall phenomena on meso- to local-scales. Prediction of the global warming should be based on precise knowledge of global content of atmospheric water vapor because of its strong green house effect. Water vapor information with high spacetime resolution are also urgently needed for the predictions of localized torrential rains, which often cause serious damage especially in western Japan.

Copy right (c) The Society of Geomagnetism and Earth, Planetary and Space Sciences (SGEPSS); The Seismological Society of Japan; The Volcanological Society of Japan; The Geodetic Society of Japan; The Japanese Society for Planetary Sciences.
To meet these requirements, water vapor information with high space-time resolution is needed. Radiosonde, one of the most reliable meteorological sensors at the moment, is not satisfactory in its space-time resolution for routine observation of atmospheric water vapor. Microwave-radiometers from space is in operation now, but they are unable to measure water vapor over land and are poor in time resolution. In this context, GPS, which can measure precipitable water vapor (PWV), the integrated water vapor in atmospheric column above the ground, is considered to be an attractive meteorological sensor. This approach is now referred to as the "Earth based GPS meteorology" (Bevis et al., 1992; Businger et al., 1996) in contrast to the "space based GPS meteorology" (see Ware et al., 1996, for details). The idea of the Earth based GPS meteorology came from the conversion of atmospheric delays as geodetic "noises" to meteorological "signals" rich in PWV information. Retrieval method of this information is straightforward, as described below.

\section{An All-Weather Giant Array Sensor of Precip- itable Water Vapor}

Propagation delays of microwave signal from GPS satellites occur both in ionosphere and neutral atmosphere. Ionospheric delays are usually removed beforehand by comparing phases simultaneously observed in multiple frequencies. Delays by neutral atmosphere (i.e. tropospheric delay) are composed of hydrostatic and wet delays. The former depends only on atmospheric pressure and can therefore be easily calculated using the pressure data at GPS sites (Davis et al., 1985). Hence wet delays are the differences between the hydrostatic delays and the tropospheric delays estimated in GPS data analysis. GPS analysis softwares treat line-ofsight tropospheric delays as the products of zenith tropospheric delays (ZTDs) and a prescribed function that maps them to arbitrary elevations, and this enables us to separate ZTDs from other parameters. Zenith wet delays (ZWDs) have been known to be proportional to PWVs; the latter being approximately 0.15 times as large as the former in unit of length (Hogg et al., 1981). This value, however, can vary 


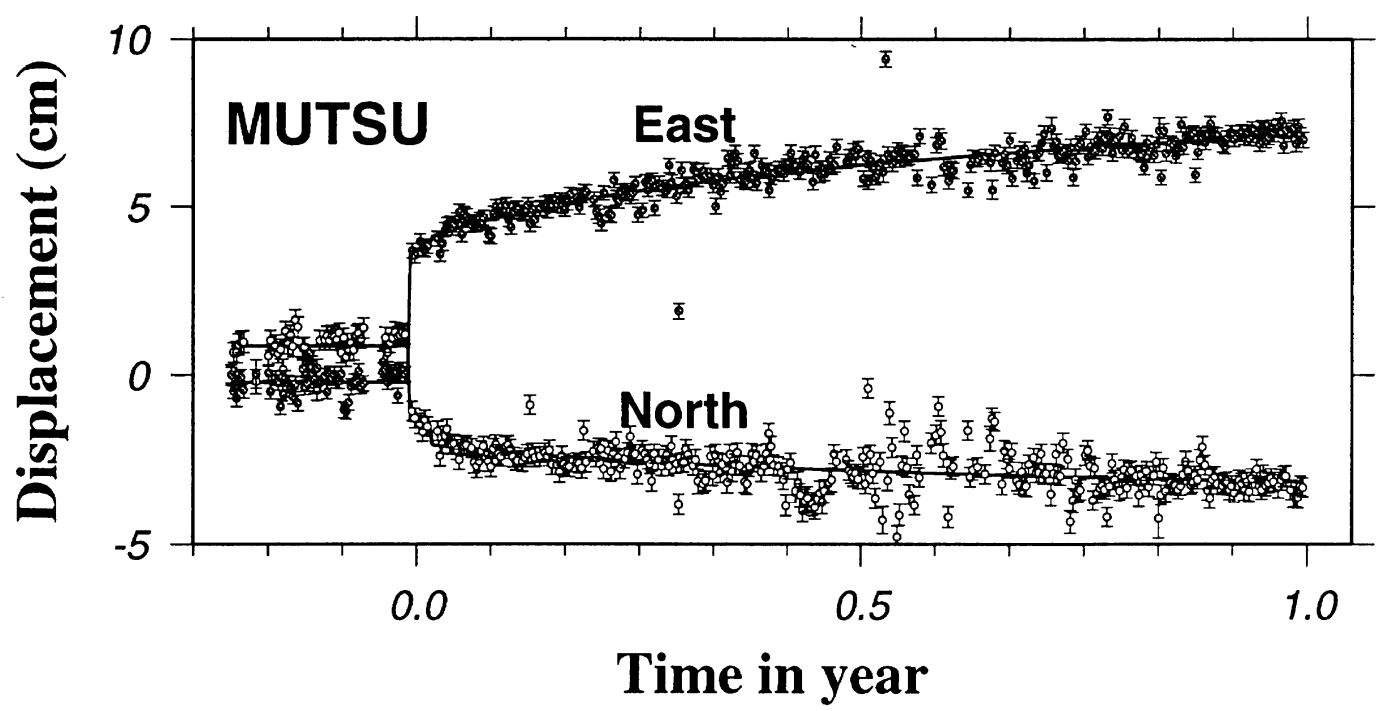

Fig. 1. The horizontal displacements at Mutsu, northern district of the main island of Japan, observed by GSI's GPS array after Sanriku-Haruka-Oki earthquake occurred Dec. 31, 1994 (Heki et al., 1997). The GPS solution in "North" shows large fluctuations in summer, that are attributable to water vapor delay noises.

as much as $15 \%$ depending on local climates (Bevis et al., 1992).

Thus, PWVs are obtained from GPS and meteorological observations at ground with these procedures. Ohtani and Naito (1998) confirmed that PWVs from GSI's GPS array agree well with those from radiosonde observations by the Japan Meteorological Agency (JMA), with RMS differences of about $3 \mathrm{~mm}$. This is surprisingly small considering the distance of up to several tens of kilometers between radiosonde stations and closest GPS sites. At the same time, these PWVs are found to have small biases (Shoji et al., 1998; Sasaki and Kimura, 1998). Using the PWV data retrieved from GSI's GPS array and the meteorological data observed by JMA over Japan, Iwabuchi et al. (1998a) clearly showed dense temporal anomalies of PWVs moved eastward across the Japanese Islands along with a front accompanied by heavy rainfalls (also see Naito et al., 1998), suggesting that GSI's array is a good all-weather giant sensor of PWV over Japan.

These PWV anomalies have been found to cause the fluctuations in the apparent site coordinates as seen in "North" in Fig. 1. Left and right figures in Fig. 2(a), respectively, shows 24 hourly anomalies of ZTDs and north-south components in site coordinates of July 17, 1996, over Japan, calculated from the three-hourly solutions in GSI's routine analysis, where the majority of the ZTD anomalies (left figure) are found to be attributable to PWVs (Iwabuchi et al., 1998b). Figure 2(b) is the weather map for Fig. 2(a) showing a front lying in west-east direction over northern Japan. Since both the anomalies in Fig. 2(a) are almost in parallel with the front lying in west-east direction, one can imagine that the observed summer fluctuations in the site coordinates shown as "North" in Fig. 1 are possibly caused by north-south oscillatory movements, with a time scale of a week or so, of a stationary front lying in an east-west direction over northern Japan similar to that shown in Fig. 2(b). Such fronts are found to be always accompanied by a dense PWV belt and to cause errors in GPS solutions (Iwabuchi et al., 1998b).

On the other hand, one may notice that the array has comparable space resolution with that of the Automated Meteorological Data Acquisition System (AMeDAS) of JMA, a nationwide surface meteorological observation network for monitoring precipitation, temperature, wind and sunshine. Combination of these two networks would thus constitute a sophisticated diagnostic system of rainfall forecast in Japan. Seko (1997) found that the detection of wet areas by the GPS array always preceded the rainfall observed by AMeDAS.

\section{GPS/MET Japan; Strategy and Goals}

"GPS/MET Japan", GPS meteorology project of Japan, was launched in April, 1997. Funded by Science and Technology Agency (STA) of Japan as a five-year project, a variety of interdisciplinary efforts have been made in geodesy, meteorology, and hydrology under the basic strategy of three major goals given below.

The first goal is to create a system to let the retrieved PWV data from GSI's nationwide GPS array flow to the 4DDA (4dimensional data assimilation) system for numerical weather prediction in JMA. This will improve the forecast systems of meso- to local-scale phenomena that often trigger torrential rains. Although the GPS array has space resolution sufficient for this purpose, it is difficult to assure near real-time PWV data production without degrading accuracy. The key issue lies in the accuracy in predicting satellite orbits, although the recent demonstration of near real-time acquisition of GPS PWV in central United States using predicted orbits is encouraging (Rocken et al., 1997a). However, real-time GPS analysis with nearly one thousand sites in Japan involving huge data transmission and computation is another problem to overcome.

On the other side, GPS PWV data assimilation would require development of a sophisticated 4DDA system in JMA. Difference between PWV data obtained from GPS made on real topography and those calculated in the 4DDA system 


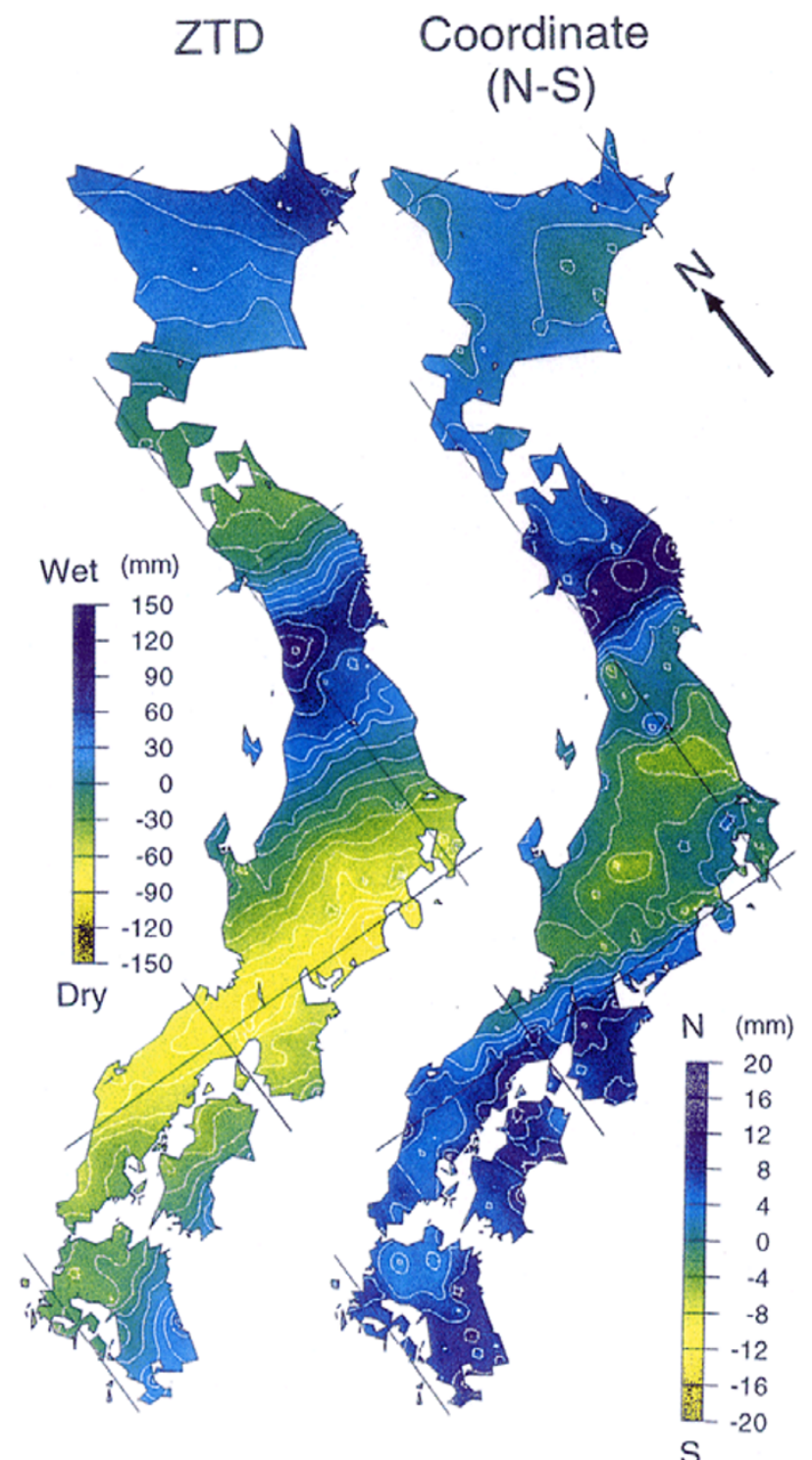

Fig. 2(a). 24 hourly anomalies of the routinely estimated ZTDs (left) and north-south components of site coordinates (right) in GSI's GPS array for July 17, 1996, while a front lies in west-east direction across the northern Japan (Iwabuchi et al., 1998b). BERNESE software is employed in the GPS routine analysis of GSI. The anomalies are obtained by removing the mean value at each point during a week.

based on model topography should be taken into account. Huge differences in height of up to several hundred meters in mountain areas may give rise to PWV difference up to about $10 \mathrm{~mm}$ (Iwabuchi et al., 1998a).

As the second goal, by using three dimensional meteorological data of JMA's 4DDA system enhanced by PWVs from GPS, we plan to establish a system diagnosing or removing the errors in estimated site coordinates due to water vapor, and to improve crustal deformation measurement accuracies. Two methods have been proposed. One is to simulate water vapor induced errors based on the improved meteorological data from JMA's 4DDA system and to identify the origin of the observed site coordinate fluctuations as shown in Fig. 1. Tentatively, the same identifications are possible using the ZTD data themselves obtained in GSI's

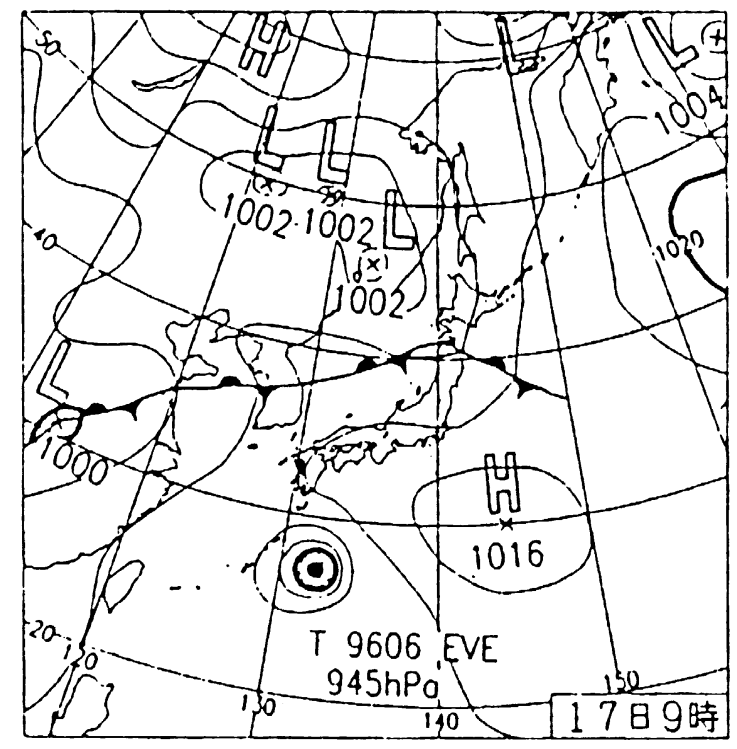

Fig. 2(b). The Japan area weather map at 00UT of July 17, 1996 (courtesy of JMA).

array as demonstrated in Fig. 2(a).

The other method is to apply atmospheric slant delays (line-of-sight delays) computed from the same meteorological data to data analyses of the GPS array. Though it needs some modifications to the data analysis software, millimeter accuracy was attained in a similar experiment in an idealized situation with radiometer observations (Alber et al., 1997).

The third goal is to construct a database of nationwide GPS PWV information for uses in interdisciplinary environmental studies, hydrology, meteorology, and geodesy. The database will contribute to atmospheric corrections in remote sensing data, air pollution research, understanding of water cycles, predictions of floods in Japan, and so on. It may also play a basic role of a permanent monitoring system of PWV change, but a more useful application would be to provide background water vapor information to crustal deformation studies by Interferometric Synthetic Aperture Radar (In-SAR). Crustal deformation data from In-SAR are also contaminated by tropospheric delays due to water vapor like those shown in Fig. 2(a), and GSI will be engaged in In-SAR research as well as GPS (e.g. Fujiwara et al., 1998).

\section{Experiments and Researches; from the Islands to the Globe}

In the project, a variety of interdisciplinary research experiments for the uses of GPS water vapor information are underway. The most basic experiment is a joint observation of GPS and radiometer at inland and coastal sites in summer to obtain information on slant wet delay as well as of ZWD during an active period in PWV's diurnal variation. It will provide fundamental data not only for the research relevant to the second goal mentioned above, but also to modeling of local circulation systems coupled with sea and land breezes in the islands that helps improve numerical prediction of local rainfalls. The most fundamental issue here is the multi-path effect on short-period estimation of the delays in GPS anal- 

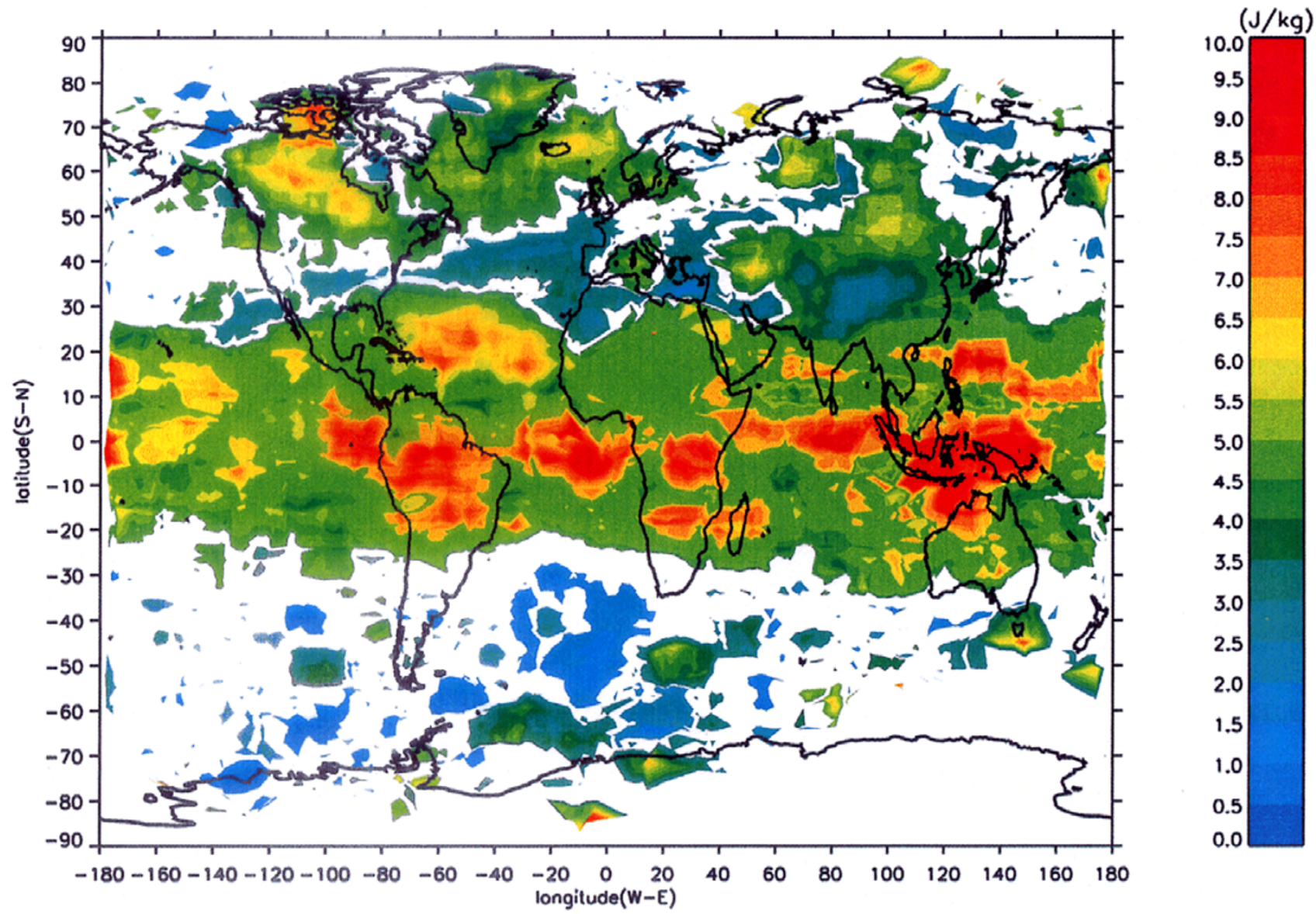

Fig. 3. A global distribution of potential energy due to atmospheric waves at altitudes of 20-30 km in November-February analyzed from the GPS occultation data provided by UCAR (Nishida and Tsuda, 1998).

ysis. There are various stochastic methods to overcome this issue, one of which is to effectively use the dense GPS array of GSI.

A joint observation of GPS PWV with satellite remote sensing of rainfalls during the rainy season of 1998 in the south-western part of Japan is a challenging experiment, where the remote sensing is conducted as one of the experiments in the Tropical Rainfall Measuring Mission (TRMM). It simultaneously acquires both PWV and precipitation data in mid torrential rainfalls. An interesting point here will be how the dedicated dense GPS array at various heights in the mountain area works as an all weather PWV sensor in mid torrential rainfalls. In the experiment, a preliminary tomography experiment of huge water vapor clusters will also be attempted by using GPS retrieved slant delay information with the aid of a numerical weather forecast model.

Thus, the project is a typical Earth based GPS meteorology project focused on water vapors over the Japanese Islands that from the meteorological point of view is complementary to other Earth based GPS meteorology projects to acquire global PWV data from the International GPS Service (IGS) network, now underway in the United States and the European Union (Businger et al., 1996; etc.), which provide basic information to understanding continental-scale water cycle.
However, the most unique point in our project is forming a positive feedback from meteorology to GPS geodesy. Its main aim is to bring out a complete ability in the world's densest GPS array by improving accuracy in GPS measurement system for crustal deformation that needs improving accuracy and resolution in numerical weather prediction system for local rainfalls, and vice versa, in the humid and earthquake-prone country of Japan.

The GPS meteorology project in Japan, therefore, is not limited to those interests in acquiring local PWV over the islands. For example, cooperative experiments with GEWEX (Global Energy and Water Cycle Experiment) Asian Monsoon Experiment (GAME), one of the sub-programs in GEWEX, are now underway with GPS measurements in Thailand, Central China, and Tibetan Plateau, in which fundamental data on both plate dynamics and water vapors will be acquired. The most interesting experiment among them may be GPS PWV observations in Thailand that are expected to provide an entirely new understanding of diurnal variation of PWV peculiar to the tropics (e.g. Watanabe et al., 1998).

The project also supports analysis of the middle atmospheric dynamics by using the temperature data retrieved by GPS occultation techniques in the space-based GPS meteorology project now conducted in the University Corporation for Atmospheric Research (UCAR) of the United States 
(Ware et al., 1996; Rocken et al., 1997b; Kuo et al., 1998).

Nishida and Tsuda (1998) have found that the GPS occultation data can describe meso-scale temperature perturbations in the stratosphere with a vertical scale ranging from 2 to $10 \mathrm{~km}$, which seem to be caused by atmospheric waves. Figure 3 shows a global distribution of potential energy due to atmospheric waves at altitudes of 20-30 km during November and February. Large wave energy is detected at low latitudes between $20^{\circ} \mathrm{N}$ and $20^{\circ} \mathrm{S}$. In particular, it is enhanced in several localized regions along the equator; the Indonesian archipelago, the Indian ocean, Eastern Atlantic Ocean, and South American sector. Figure 3 strongly suggests that atmospheric waves are actively generated by tropical convection, which will provide valuable information for the tropical middle atmospheric dynamics, such as the behavior of QuasiBiennial Oscillation (QBO).

So far Japan has made only small contributions to the innovation of GPS technology but developed the world's densest GPS array for mitigating earthquake disasters. The project is basically motivated with our awareness of Japan as the world's largest GPS user in Earth sciences. As a part of the campaign, we also plan to hold the international GPS symposium at Tsukuba near Tokyo on Oct. 18-22, 1999, at which we will present the highlights of the first half of the project.

Acknowledgments. We thank the Japan Weather Association and the Japanese Association of Surveying for their cooperation in the project. We also thank A. Yamada of GSI for her continuous GPS data support. We would especially like to express our thanks to the late A. Nomura for his invaluable efforts in launching the project. Temperature profiles with the GPS occultation measurements are provided by the UCAR GPS/MET office. Thanks are also extended to P. L. Dyson and B. F. Chao for their comments to the draft.

\section{References}

Alber, C., R. Ware, C. Rocken, and F. Solheim, GPS surveying with $1 \mathrm{~mm}$ precision using corrections for atmospheric slant path delay, Geophys. Res. Lett., 24, 1859-1862, 1997.

Bevis, M., S. Businger, T. A. Herring, C. Rocken, R. A. Anthes, and R. H. Ware, Remote sensing of atmospheric water vapor using the Global Positioning System, J. Geophys. Res., 97, 15787-15801, 1992.

Businger, S., S. R. Chiswell, M. Bevis, J. Duan, R. Anthes, C. Rocken, R. H. Ware, T. M. Exner, T. Van Hove, and F. Solheim, The promise of GPS in atmospheric monitoring, Bull. Amer. Met. Soc., 77, 5-17, 1996.

Davis, J. L., T. A. Herring, I. I. Shapiro, A. E. Rogers, and G. Elgered, Geodesy by Radio Interferometry: Effects of atmospheric modeling errors on estimates of baseline length, Radio Sci., 20, 1593-1607, 1985.

Fujiwara, S., P. A. Rosen, M. Tobita, and M. Murakami, Crustal deformation measurements using repeat-pass JERS 1 synthetic aperture radar interferometry near the Izu Peninsula, Japan, J. Geophys. Res., 103, 2411-2426, 1998.

Heki, K., S. Miyazaki, and H. Tsuji, Silent fault slip following an interplate thrust earthquake at the Japan Trench, Nature, 386, 595-598, 1997.

Hogg, D. C., F. Guiraud, and M. Decker, Measurements of excess transmission length on earth-space path, Astron. Astrophys., 95, 304-307, 1981.

Iwabuchi, T., I. Naito, and N. Mannoji, Behaviors of GPS retrieved precipitable water vapor over the Japanese islands, J. Met. Soc. Japan, 1998a (submitted)

Iwabuchi, T., I. Naito, and K. Chida, A close relationship between temporal anomalies in site coordinates and zenith tropospheric delays in GPS array over Japan, Earth Planets Space, 1998b (to be submitted).

Kuo, Y.-H., X. Zou, S. J. Chen, W. Huang, Y.-R. Guo, R. A. Anthes, M. Exner, D. Hunt, C. Rocken, and S. Sokolovsky, A GPS/MET sounding through an intense upper-level front, Bull. Amer. Meteorol. Soc., 79, 617$626,1998$.

Naito, I., Y. Hatanaka, N. Mannoji, R. Ichikawa, S. Shimada, T. Yabuki, H. Tsuji, and T. Tanaka, Global positioning system project to improve Japanese weather, earthquake predictions, EOS, 79, No. 26, p. 301, 308, $311,1998$.

Nishida, M. and T. Tsuda, Global distribution of temperature variations due to atmospheric gravity waves estimated from GPS occultation techniques, Proceedings of Spring Meeting of Met. Soc. Japan, 321, 1998 (in Japanese).

Ohtani, R. and I. Naito, Evaluations of GPS retrieved precipitable water vapors with radiosonde observations over Japan, J. Met. Soc. Japan, 1998 (submitted).

Rocken, C., T. Van Hove, and R. Ware, Near real-time GPS sensing of atmospheric water vapor, Geophys. Res. Lett., 24, 3221-3224, 1997a.

Rocken, C., R. Anthes, M. Exner, D. Hunt, S. Solokovskiy, R. Ware, M. Gorbunov, W. Schreiner, D. Feng, B. Herman, Y.-H. Kuo, and X. Zou, Analysis and validation of GPS/MET data in the neutral atmosphere, $J$. Geophys. Res., 102, 29849-29866, 1997b.

Sasaki, T. and F. Kimura, Diurnal variations in precipitable water vapors from radiosonde and GPS observations, Proceedings of Spring Meeting of Met. Soc. Japan, 257, 1998 (in Japanese).

Seko, H., Variation of GPS retrieved precipitable water vapor (2), KISYOU, 42, 15463-15467, 1997 (in Japanese).

Shoji, Y., H. Seko, A. Ichiki, K. Aonashi, and H. Nakamura, Analyses of GPS retrieved precipitable water vapor observed during "1997 GPS/MET Summer Campaign at Tsukuba", Proceedings of Spring Meeting of Met. Soc. Japan, 208, 1998 (in Japanese).

Tsuji, H., Y. Hatanaka, and S. Miyazaki, Tremors! monitoring crustal deformation in Japan, GPS World, 7, No. 4, 18-30, 1996.

Ware, R., M. Exner, D. Feng, M. Gorbunov, K. Hardy, B. Herman, Y. Kuo, T. Meehan, W. Melbourn, C. Rocken, W. Shreiner, S. Solokovskiy, F. Solheim, X. Zou, R. Anthes, S. Businger, and K. Trenberth, GPS sounding of the atmosphere from low earth orbit: Preliminary results, Bull. Amer. Meteorol. Soc., 77, 19-40, 1996.

Watanabe, A., T. Ohsawa, Y. Tachibana, D. Yamanaka, K. Furukawa, T. Tamai, K. Nakajima, Y. Shibagaki, M. Kajiwara, T. Pogrermdee, T. Saeweekun, C. Chanplong, W. Samroeng, D. Bisonyabut, P. Patvivatsiri, A. Sumi, and K. Musiaki, Why do rainfalls frequently occur in midnight in the northern part of Thailand?, Proceedings of Spring Meeting of Met. Soc. Japan, 163, 1998 (in Japanese).

T. Tsuda (e-mail: tsuda@kurask.kyoto-u.ac.jp), K. Heki, S. Miyazaki, K. Aonashi, K. Hirahara, H. Nakamura, M. Tobita, F. Kimata, T. Tabei, T. Matsushima, F. Kimura, M. Satomura, T. Kato, and I. Naito (e-mail: naito@miz.nao.ac.jp) 